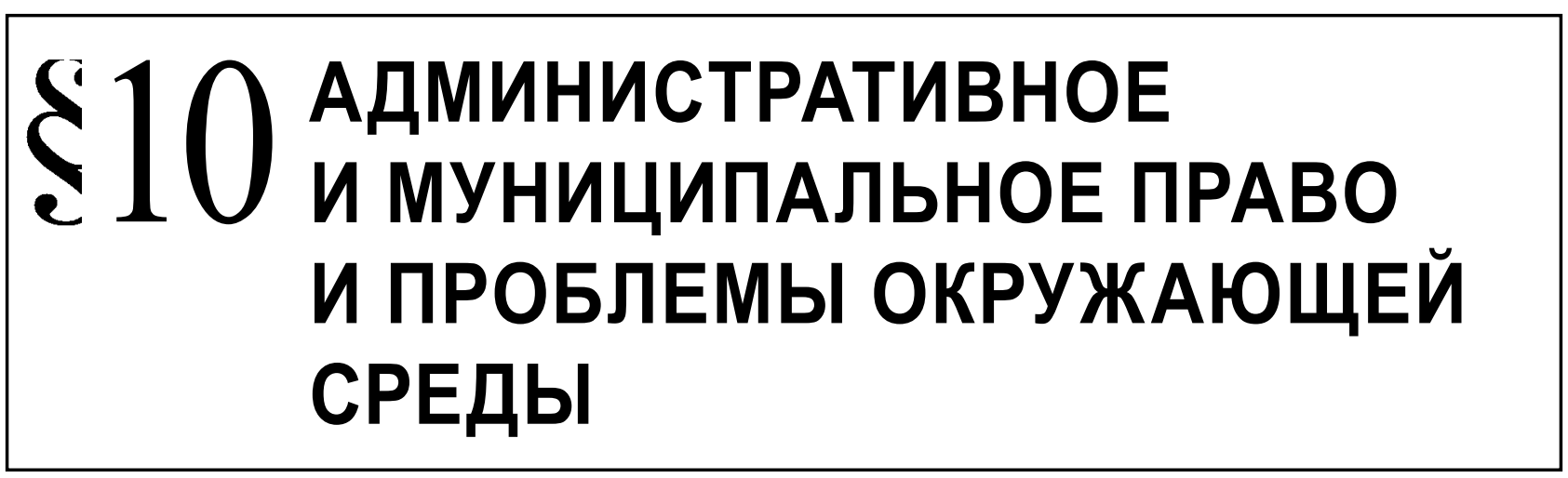

Кожевников О.А.

\title{
СОВЕРШЕНСТВОВАНИЕ СУДЕБНОЙ ПРАКТИКИ ПО ВОПРОСАМ ОБРАЩЕНИЯ С ОТХОДАМИ ПРОИЗВОДСТВА И ПОТРЕБЛЕНИЯ КАК ОДНА ИЗ ЗАДАЧ «ОБНОВЛЕННОГО» ВЕРХОВНОГО СУДА РФ
}

\begin{abstract}
Аннотация: Предметом данной статьи является анализ правового регулирования общественных отношений, которые возникают в срере обращения с отходами производства и потребления, а также складывающейся судебной практики, которая однозначно указывает в качестве "крайнего" при неисполнении хозяйствующими субъектами и собственниками земельных участков своих обязанностей по обеспечению конституционных прав граждан на благоприятную окружающую среду исключительно органы местного самоуправления в лице Администраций муниципальных образований, без надлежащего исследования всего комплекса правового регулирования данного вида экологических правоотношений. Общенаучные методы( диалектический, функциональный, логический) и частнонаучные правовые методы(метод сравнительного правоведения, формально-юридический метод, метод юридического моделирования и др.) На основе анализа комплекса нормативно-правовых актов в срере обеспечения экологических прав граждан, сложившейся судебной практики делается вывод о "сомнительности" исключительной ответственности органов местного самоуправления в связи с выявляемыми органами контроля и надзора нарушениями экологического, санитарно-эпидемиологического и иного законодательства хозяйствующими субъектами, выражающиеся в появлении на территориях муниципальных образований несанкционированных свалок бытовых и промышленных отходов. Автор полагает, исключение из числа ответственных лии, граждан и юридических лиц - собственников отходов, а также собственников земельных участков, на которых обнаружены несанкционированные свалки отходов порождает безнаказанность указанных лиц и безосновательно возлагает на органы местного самоуправления обязанности по ликвидации обнаруженных свалок отходов.

Ключевые слова: верховный суд, конститучионный суд, местное самоуправление, конституция, экологические права, отходы потребления, судопроизводство, судебная практика, санитарное законодательство, вопросы местного значения.
\end{abstract}

$\mathrm{P}$ азвитие политической, общественной жизни в РФ, переход к рыночным основам в экономике способствовал не только возникновению прогресса в производственных и связанных с ними отношениях, но, к сожалению, привел и к целому ряду негативных моментов, которые усугубляются неурегулированностью целого ряда вновь возникших общественных отношений. Увеличение промышленного потенциала, использования природных ресурсов и недр усилило негативное влияние научно-технических факторов на окружающую природную среду. Ситуация усугубляется и тем фактом, что за период постсоветского этапа истории России резко снизился уровень правовой и общей культуры населения при реализации гражданами своего конституционного права на свободное владение, пользование и распоряжение природными ресурсами. Конституция Российской Федерации, провозглашая признание, соблюдение и защиту прав и свобод человека и гражданина 
обязанностью государства (статья 2), гарантирует каждому свободу экономической деятельности, право иметь имущество в собственности, владеть, пользоваться и распоряжаться им как единолично, так и совместно с другими лицами, экологические права и защиту указанных прав и свобод, в том числе судебную защиту, реализуемую на основе равенства всех перед законом и судом (статья 8; статья 19 , части 1 и 2 ; статья 35 , ст. 42 , части 1 и 2 ; статья 45 , часть 1 ; статья 46 , часть 1 ).

Конституционный Суд Российской Федерации неоднократно в своей практике прямо или косвенно в своих решениях затрагивал вопросы использования природных ресурсов и защиты экологических прав граждан. В частности в постановлении от 23 апреля 2004 г. № 8-П «По делу о проверке конституционности Земельного кодекса Российской Федерации в связи с запросом Мурманской областной Думы» Конституционный Суд Российской Федерации пришел к следующим выводам: “Конституционная характеристика земли как основы жизни и деятельности народов, проживающих на соответствующей территории, то есть всего многонационального народа Российской Федерации, предопределяет конституционное требование рационального и эффективного использования, а также охраны земли как важнейшей части природы, естественной среды обитания человека, природного ресурса, используемого в качестве средства производства в сельском и лесном хозяйстве, основы осуществления хозяйственной и иной деятельности. Это требование адресовано государству, его органам, гражданам, всем участникам общественных отношений, является базовым для законодательного регулирования в данной сфере и обусловливает право федерального законодателя устанавливать особые правила, порядок, условия пользования землей"

Согласно Постановлению Конституционного Суда РФ от 5 марта 2013 г. № 5-П «По делу о проверке конституционности статьи 16 Федерального закона «Об охране окружающей среды» и Постановления Правительства Российской Федерации «Об утверждении Порядка определения платы и ее предельных размеров за загрязнение окружающей природной среды, размещение отходов, другие виды вредного воздействия» в связи с жалобой общества с ограниченной ответственностью

\footnotetext{
1 См.: По делу о проверке конституционности Земельного кодекса Российской Федерации в связи с запросом Мурманской областной Думы // СЗ РФ. 2004. № 18. Ст. 1833.
}

«Тополь» обязанность, предусмотренная в ст. 58 Конституции, имеет всеобщий характер и, будучи частью обеспечительного механизма реализации экологических прав граждан, распространяется как на граждан, так и на юридические лица, что с необходимостью предполагает и их ответственность за состояние экологии. Поскольку эксплуатация природных ресурсов, их вовлечение в хозяйственный оборот наносят ущерб окружающей среде, издержки по осуществлению государством мероприятий по ее восстановлению в условиях рыночной экономики должны покрываться прежде всего за счет субъектов хозяйственной и иной деятельности. Публичная власть, также несущая конституционную ответственность за сохранение природы, в свою очередь, обязана принимать меры, направленные на сдерживание загрязнения окружающей среды, предупреждение и минимизацию экологических рисков ${ }^{2}$.

Важность вопросов правового регулирования загрязнения окружающей природной среды обусловили необходимость по-новому взглянуть на комплекс вопросов по обеспечению экологических прав граждан, а также практику судебных органов при разрешении вопросов борьбы с несанкционированными свалками постоянно появляющимися как в местах производственной деятельности хозяйствующих субъектов, так и в местах массового отдыха граждан.

В соответствии со ст. 72 Конституции Российской Федерации вопросы природопользования, охраны окружающей среды и обеспечения экологической безопасности находятся в совместном ведении Российской Федерации и субъектов Российской Федерации.

На федеральном уровне, правовые основы государственной политики в области охраны окружающей среды определяет Федеральный закон от 10.01.2002 № 7-Ф3 «Об охране окружающей среды», который регулирует отношения в сфере взаимодействия общества и природы, возникающие при осуществлении хозяйственной и иной

\footnotetext{
2 Постановление Конституционного Суда Российской Федерации от 5 марта 2013 г. № 5-П “По делу о проверке конституционности статьи 16 Федерального закона "Об охране окружающей среды” и Постановления Правительства Российской Федерации “Об утверждении Порядка определения платы и ее предельных размеров за загрязнение окружающей природной среды, размещение отходов, другие виды вредного воздействия" в связи с жалобой общества с ограниченной ответственностью “Тополь” // СЗ РФ. 2013. № 11. Ст. 1164.
} 
деятельности, связанной с воздействием на природную среду как важнейшую составляющую окружающей среды, включая вопросы ответственности за нарушение законодательства в области охраны окружающей среды.

Правовое регулирование в области обращения с отходами осуществляется Федеральным законом от 24.06.1998 № 89-Ф3 «Об отходах производства и потребления», другими законами и иными нормативными правовыми актами Российской Федерации, законами и иными нормативными правовыми актами субъектов Российской Федерации, а также муниципальными нормативными правовыми актами.

Согласно ч. 3 ст. 8 Закона № 89-ФЗ от 24.06.1998 «Об отходах производства и потребления» к полномочиям органов местного самоуправления городских округов в области обращения с отходами относится организация сбора, вывоза, утилизации и переработки бытовых и промышленных отходов.

В силу п. 2, п. 3 ст. 13 указанного Закона организацию деятельности в области обращения с отходами на территориях муниципальных образований осуществляют органы местного самоуправления в соответствии с законодательством Российской Федерации.

В силу пункта 24 части 1 статьи 16 Федерального закона от 6 октября 2003 г. № 131-Ф3 «Об общих принципах организации местного самоуправления в Российской Федерации» к полномочиям органов местного самоуправления городских округов в области обращения с отходами относится организация сбора, вывоза, утилизации и переработки бытовых и промышленных отходов.

Из системного толкования приведенных выше положений законодательства РФ следует, что органы местного самоуправления могут выступать, с одной стороны, как юридические лица, осуществляющие деятельность по обращению с отходами, a, с другой стороны, являются органами, осуществляющими лишь организацию деятельности в области обращения с отходами на территориях соответствующих муниципальных образований.

Вместе с тем, судебная практика устойчиво вышеуказанный вывод опровергает и при разрешении гражданско-правовых споров об обязании ликвидировать несанкционированные свалки бытовых и промышленных отходов на территории муниципального образования возлагают указанную обязанность исключительно на Администрации муниципальных образований, поскольку вышеуказанные свалки бытовых и промышленных отходов обнаружены в пределах территории муниципального образования ${ }^{3}$. Полагаем, что такое положение вещей весьма сомнительно с точки зрения буквального толкования нормы российского законодательства и соблюдения конституционных гарантий местного самоуправления.

Согласно статье 1 Закона № 89-ФЗ «Об отходах производства и потребления» под отходами производства и потребления понимаются остатки сырья, материалов, полуфабрикатов, иных изделий или продуктов, которые образовались в процессе производства или потребления, а также товары (продукция), утратившие свои потребительские свойства.

Исходя из статьи 1 указанного Закона обращение с отходами - это деятельность по сбору, накоплению, использованию, обезвреживанию, транспортированию, размещению отходов.

В соответствии с частями 1 и 2 статьи 51 Закона № 7-Ф3 «Об охране окружающей среды» отходы производства и потребления, в том числе радиоактивные отходы, подлежат сбору, использованию, обезвреживанию, транспортировке, хранению и захоронению, условия и способы которых, должны быть безопасными для окружающей среды и регулироваться законодательством Российской Федерации. Запрещается сброс отходов производства и потребления, в том числе радиоактивных отходов, в поверхностные и подземные водные объекты, на водосборные площади, в недра и на почву.

Согласно части 1 статьи 13 Земельного кодекса РФ в целях охраны земель собственники земельных участков, землепользователи, землевладельцы и арендаторы земельных участков обязаны проводить мероприятия по защите земель от захламления отходами производства и потребления и ликвидации последствий захламления земель. Собственники земельных участков и лица, не являющиеся собственниками земельных участков, обязаны: использовать земельные участки в соответствии с их целевым назначением и принадлежностью к той или иной категории земель и разрешенным использованием способами, которые не должны наносить вред окружающей среде, в том числе земле как природному объекту; не допускать загрязнение, захламление, деградацию и ухудшение плодородия почв на землях соответствующих категорий (статья 42 ЗК РФ).

\footnotetext{
См. Например Определение Свердловского областного суда от 28 июня 2013 г. по делу № 33-7322/2013, Решение Свердловского областного суда от 13 марта 2013 г. по делу № 71-75/2013.
} 
Статьей 12 Закона №89-ФЗ «Об отходах производства и потребления» установлены требования к объектам размещения отходов. Запрещается размещение отходов на объектах, не внесенных в государственный реестр объектов размещения отходов (часть 7 статьи 12 Закона № 89-ФЗ).

Согласно части 1 статьи 19 Закона № 89-Ф3 «Об отходах производства и потребления» индивидуальные предприниматели и юридические лица, осуществляющие деятельность в области обращения с отходами, обязаны вести в установленном порядке учет образовавшихся, использованных, обезвреженных, переданных другим лицам или полученных от других лиц, а также размещенных отходов. Порядок учета в области обращения с отходами утвержден Приказом Минприроды России от 01.09.2011 № 721 .

В соответствии с п. 1 ст. 4 вышеуказанного Закона право собственности на отходы принадлежит собственнику сырья, материалов, полуфабрикатов, иных изделий или продуктов, а также товаров (продукции), в результате использования которых эти отходы образовались.

Статьей 11 Федерального закона от 24.06.1998 № 89-Ф3 «Об отходах производства и потребления» установлено, что индивидуальные предприниматели и юридические лица при эксплуатации предприятий, зданий, строений, сооружений и иных объектов, связанной с обращением с отходами, обязаны, в том числе: соблюдать экологические, санитарные и иные требования, установленные законодательством Российской Федерации в области охраны окружающей среды и здоровья человека; разрабатывать проекты нормативов образования отходов и лимитов на размещение отходов в целях уменьшения количества их образования; проводить инвентаризацию отходов и объектов их размещения; проводить мониторинг состояния окружающей среды на территориях объектов размещения отходов; предоставлять в установленном порядке необходимую информацию в области обращения с отходами.

В силу ст. 11 Федерального закона № 52-Ф3 «0 санитарно-эпидемиологическом благополучии населения» индивидуальные предприниматели и юридические лица в соответствии с осуществляемой ими деятельностью обязаны выполнять требования санитарного законодательства, а также постановлений, предписаний осуществляющих федеральный государственный санитарно-эпидемиологический надзор должностных лиц.
Согласно п. 1 ст. 22 Федерального закона № 52-Ф3 «0 санитарно-эпидемиологическом благополучии населения» отходы производства и потребления подлежат сбору, использованию, обезвреживанию, транспортировке, хранению и захоронению, условия и способы которых должны быть безопасными для здоровья населения и среды обитания и которые должны осуществляться в соответствии с санитарными правилами и иными нормативными правовыми актами Российской Федерации.

В соответствии с ч. 2 ст. 39 Федерального закона от 10.01.2002 № 7-ФЗ «Об охране окружающей среды» юридические и физические лица, осуществляющие эксплуатацию зданий, строений, сооружений и иных объектов, обеспечивают соблюдение нормативов качества окружающей среды на основе применения технических средств и технологий обезвреживания и безопасного размещения отходов производства и потребления, обезвреживания выбросов и сбросов загрязняющих веществ, а также иных наилучших существующих технологий, обеспечивающих выполнение требований в области охраны окружающей среды, проводят мероприятия по восстановлению природной среды, рекультивации земель, благоустройству территорий в соответствии с законодательством.

В силу ч. 1 ст. 51 указанного Закона отходы производства и потребления подлежат сбору, использованию, обезвреживанию, транспортировке, хранению и захоронению, условия и способы которых, должны быть безопасными для окружающей среды и регулироваться законодательством Российской Федерации.

Таким образом, система действующего законодательства в области охраны окружающей среды и обращения с отходами возлагает на граждан, хозяйствующих субъектов в соответствии с осуществляемой ими деятельностью обязаны выполнять требования санитарного законодательства и экологического законодательства, в том числе и в части обращения отходов производства и потребления.

В тоже время, исходя из системного толкования законодательства о местном самоуправлении, экологического, санитарно-эпидемиологического и гражданского законодательства органы местного самоуправления в правоотношениях по обращению отходов производства и потребления могут выступать, с одной стороны, как юридические лица, осуществляющие деятельность по обраще- 
нию с отходами, a, с другой стороны, как органы осуществляющие организацию деятельности в области обращения с отходами на территориях соответствующих муниципальных образований ${ }^{4}$.

В связи с этим возлагать обязанностей по ликвидации несанкционированных свалок бытовых и промышленных отходов на исполнительно-распорядительные органы местного самоуправления возможно лишь в том случае, если указанные отходы появились в результате их хозяйственной деятельности как юридических лиц, в области обращения с отходами по утилизации и переработки бытовых и промышленных отходов.

В случае, если несанкционированные свалки бытовых и промышленных отходов обнаружены уполномоченными контрольными или надзорными органами, указанные органы обязаны установить собственника указанных бытовых (промышленных) отходов или собственника (владельца) земельного участка.

Ответственность последнего наступает, по нашему мнению, в связи с тем, что согласно подпунктам 2 и 4 пункта 1 статьи 13 Земельного кодекса РФ в целях охраны земель собственники земельных участков, землепользователи, землевладельцы и арендаторы земельных участков обязаны проводить мероприятия по защите земель от захламления отходами производства и потребления; ликвидации последствий загрязнения, в том числе биогенного загрязнения, и захламления земель.

Статьей 42 Земельного кодекса РФ установлено, что собственники земельных участков и лица, не являющиеся собственниками земельных участков, обязаны не допускать, в том числе загрязнение и захламление почв.

Полагаем, что организация сбора, вывоза, утилизации и переработки бытовых и промышлен- ных отходов является властно-распорядительной функцией органов местного самоуправления и далеко не всегда влечет за собой несоблюдение гражданами, хозяйствующими субъектами своих обязанностей по соблюдению законодательства в сфере обращения с бытовыми и промышленными отходами.

Одним из фундаментальных принципов современного гражданского и арбитражного процесса является принцип непосредственности судебного разбирательства. Ее сущность, состоит в обеспечении личного восприятия и исследования судом всех обстоятельств, необходимых для установления фактических обстоятельств дела и выраженных в представленных средствах доказывания. Только всесторонне, полно и объективно исследованные судом доказательства, получившие оценку, основанную на внутреннем убеждении судьи, могут быть положены им в основание принимаемого по делу судебного акта. Иное означает нарушение тесной связи принципа непосредственности судебного разбирательства и требования свободной оценки доказательств в судебном процессе, что в свою очередь влечет за собой нарушение прав на судебную защиту.

В связи с этим, полагаем, что обновленному Верховному Суду РФ настало время обобщить судебную практику законодательства в сфере обращения отходов производства и потребления и четко разграничить, а может в отдельных случаях и объединить ответственность граждан, хозяйствующих субъектов за неисполнение законодательства в вышеуказанной сфере и органов местного самоуправления в части полноты исполнения своих властно-распорядительных функций именно по организации сбора, вывоза, утилизации и переработки бытовых и промышленных отходов.

\section{Библиография:}

1. Постановление Конституционного суда РФ от 23 апреля 2004 г. № 8-П «По делу о проверке конституционности Земельного кодекса Российской Федерации в связи с запросом Мурманской областной Думы» // СЗ РФ. 2004 . № 18. Ст. 1833

2. Постановление Конституционного Суда Российской Федерации от 5 марта 2013 г. № 5-П "По делу о проверке конституционности статьи 16 Федерального закона "Об охране окружающей среды" и Постановления Правительства Российской Федерации "Об утверждении Порядка определения платы и ее предельных размеров за загрязнение окружающей природной среды, размещение отходов, другие виды вредного воздействия" в связи с жалобой общества с ограниченной ответственностью "Тополь" // СЗ РФ. 2013. № 11. Ст. 1164.

3. Конституция РФ //СР РФ.2014. № 15, ст. 1691.

4. Федеральный закон от 10.01.2002 № 7-ФЗ «Об охране окружающей среды» http://www.pravo.gov.ru-12.03.2014

4 См. например Постановление Верховного Суда РФ от

13.05.2014 по делу №65-АД14-2. 


\section{Административное и муниципальное право $9(81) \cdot 2014$}

5. Федеральный закон от 24.06.1998 № 89-Ф3 "Об отходах производства и потребления" /Российская газета, № 121 , 30.06.1998

6. Федеральный закон от 06.10.2003 № 131-Ф3 "Об общих принципах организации местного самоуправления в Российской Федерации" http://www.pravo.gov.ru-24.06.2014

7. Федеральный закон от 30.03.1999 № 52-Ф3 "О санитарно-эпидемиологическом благополучии населения" //С3 РФ. 1999. № 14, ст. 1650

\section{References (transliterated):}

1. Postanovlenie Konstitutsionnogo suda RF ot 23 aprelya 2004 g. № 8-P «Po delu o proverke konstitutsionnosti Zemel'nogo kodeksa Rossiiskoi Federatsii v svyazi s zaprosom Murmanskoi oblastnoi Dumy» // SZ RF. 2004. № 18. St. 1833

2. Postanovlenie Konstitutsionnogo Suda Rossiiskoi Federatsii ot 5 marta 2013 g. № 5-P "Po delu o proverke konstitutsionnosti stat'i 16 Federal'nogo zakona "Ob okhrane okruzhayushchei sredy" i Postanovleniya Pravitel'stva Rossiiskoi Federatsii "Ob utverzhdenii Poryadka opredeleniya platy i ee predel'nykh razmerov za zagryaznenie okruzhayushchei prirodnoi sredy, razmeshchenie otkhodov, drugie vidy vrednogo vozdeistviya" v svyazi s zhaloboi obshchestva s ogranichennoi otvetstvennost'yu "Topol'" // SZ RF. 2013. № 11. St. 1164.

3. Konstitutsiya RF //SP RF.2014. № 15, st. 1691.

4. Federal'nyi zakon ot 10.01.2002 № 7-FZ «Ob okhrane okruzhayushchei sredy» http://www.pravo.gov.ru-12.03.2014

5. Federal'nyi zakon ot 24.06.1998 № 89-FZ "Ob otkhodakh proizvodstva i potrebleniya" /Rossiiskaya gazeta, № 121, 30.06.1998

6. Federal'nyi zakon ot 06.10 .2003 № 131-FZ "Ob obshchikh printsipakh organizatsii mestnogo samoupravleniya v Rossiiskoi Federatsii" http://www.pravo.gov.ru-24.06.2014

7. Federal'nyi zakon ot 30.03.1999 № 52-FZ "O sanitarno-epidemiologicheskom blagopoluchii naseleniya" //CZ RF. 1999. № 14 , st. 1650 